\title{
MODERN AGILE LEARNING ENVIRONMENT
}

\author{
S. Morcov \\ Katholieke Universiteit Leuven (BELGIUM)
}

\begin{abstract}
The skills required by modern organizations and their experts to remain competitive change faster and faster in today's world. In order to foster complexity, the learning and eLearning environment of the future is agile in all aspects, starting from the technical infrastructure and the managerial approach to implementation, to the learning content and learning itself. This paper proposes an integrated holistic formal concept, the Agile Learning Environment. It presents the conceptual processes, functional architecture and technology platform for an eLearning and collaboration platform able to support it, and approaches to collaborative content creation and knowledge building. The approach starts from rigorous stakeholder management, based on the concept of Circles of Knowledge - overlapping communities of interest and expertise. The border between trainer and trainee is no longer clearly defined in modern knowledge-building environments, hence stakeholder management must be particularly agile. The complexity of today's organizations requires special complexity management methods and skills, but more than this, it also offers significant opportunities, through such characteristics associated with dynamic complexity such as emergence and innovation. The paper uses qualitative research, based on actual project cases.
\end{abstract}

Keywords: eLearning, collaborative learning, agile learning, e-Learning, knowledge building, Circles of Knowledge.

\section{INTRODUCTION}

The skills required by modern organizations and experts to remain competitive change faster and faster. The internal learning curve is always shorter: content is created and becomes obsolete in short cycles, sometimes in just a few months. Staff moves horizontally as well as vertically through the organizational charts, to acquire new insights and competences, to foster innovation and exchange of information across organizations. New technology such as Robotic Process Automation (RPA) and Artificial Intelligence (Al makes yesterday's jobs obsolete, while new job types are created daily.

In modern organizations, stakeholders switch roles frequently between trainer and trainee. Experts contribute to training content as much as they benefit from it. The barrier between learner and trainer is no longer clear. To support today's organizations' needs, a new agile approach to training is required; a new paradigm that supports collaborative learning and knowledge creation, flexible learning styles, short learning and induction cycles; in order to drive organizational innovation, competitiveness and growth.

This paper proposes a formalization of the modern Agile Learning Environment, based on a constructivist pedagogical foundation and on using agility to foster complexity. It takes into account various aspects of complexity, including structural and dynamic, technological and organizational [1] [2] [3] [4] [5]

The pedagogy/andragogy foundation is grounded on constructivism [6] [7]. This is operationalized as knowledge building [8], namely collaborative learning and information sharing in groups of expertise - overlapping knowledge communities - Circles of Knowledge [9]. The main aspect is that the learning paradigm changes from a traditional unidirectional, top-down, trainer-to-trainees approach, to a community-driven, bottom-up approach. This strategy is particularly well adapted to suit the needs of the modern adult professionals:

- highly motivated;

- has a high level of expertise;

- learns, innovates and creates knowhow continuously, at work, on-the-job. In fact, $68 \%$ of employees prefer now to learn at work [10].

- changes frequently role and required competencies; 
- knows more about certain topics than trainers;

- have limited time available [11].

The mid-2000s introduced the eLearning 2.0 paradigm, based on virtual collaboration and communication environments, web 2.0 tools, delivery of personalized multimedia-rich content, projectbased learning, and collaborative learning environments, developed according to scientific pedagogy principles [12] [13] [14]. This paradigm already embraced the principle that computer education is still education, and eLearning is learning. But more than this, modern learning and education is also necessarily eLearning and digital learning. Thus, the modern Agile Learning Environment is an eLearning environment.

\section{METHODOLOGY}

The approach for this research was qualitative, exploratory and descriptive. It is based on crosssectional study of recent actual project cases. Conclusions are drawn from analyzing common approaches between these projects, evaluating new modern tendencies and through generalization and abstraction. The cases represent large complex programs for training, eLearning, communication and capacity building, at international level, covering large user bases, in numerous varied geographic regions and countries, in many different languages. This matches generally accepted definitions of complex projects [15] [16]. Qualitative research supports understanding new scientific areas [17]. Multiple case studies support building new theories and their external validation. Research based on case studies allows for emergent strategies, being among the most impactful approaches [18].

\subsection{Case-study: Epale - Electronic Platform for Adult Learning in Europe}

The program aims to support the European Union's (EU) policy on adult education, being implemented by the European Commission - Education, Audiovisual and Culture Executive Agency (EACEA), together with DG Education, DG Employment and supported by DG Digit. The overall objectives are to support the implementation of the European Pillar of Social Rights and the Council Resolution on a Renewed European Agenda for Adult Learning and its successor texts; contributing to the development of an active online community of adult learning professionals in all participating countries; making available on the internet high quality and accurate information and advice for adult learning professionals in Europe about adult learning policy, provision and practice; and fostering the development of the skills of adult education professionals, including by facilitating their participation in continuous professional development. It covers all 36 countries participating in the Erasmus+ Programme, being supported by autonomous National Support Services in each participating country. The platform has 50,000 registered users and a catalogue of 9,000 educational resources [19].

\subsection{Case-study: B-Train - EU-wide training programme in the field of customs and taxation}

B-Train, implemented by the European Commission - Directorate-General Taxation and Customs Union (DG Taxud), is the integrated capacity building program for supporting experts, officials in customs and taxation and economic operators throughout Europe, to be informed, learn, be certified, communicate and exchange best practice, to increase efficiency in the implementation of the European Customs Union regulations and of the European Customs and Taxation Competency Framework. It supports the implementation of Customs 2020 and Fiscalis 2020 programmes. It includes development and deployment of eLearning modules, platform and tools, capacity building, EU-wide communication and consultancy. It covers 35 Participating Countries and all their languages [20].

\subsection{Case-study: Consumer Champion}

The project was implemented by CHAFEA - the Consumers, Health and Food Executive Agency of the European Commission, together with DG Justice (initially DG Sanco). Its objective was to build the capacity and effectiveness of consumer organizations, by training, a collaboration web portal and virtual community, development of multimedia eLearning courses and an eLearning portal, translation in 11 languages. It targeted cca. 5,000 users from multiple stakeholder organizations in all EU countries. 


\subsection{Case-study: Consumer Classroom}

The project was implemented by CHAFEA - the Consumers, Health and Food Executive Agency of the European Commission, together with DG Justice (initially DG Sanco). Its objective was to promote consumer education and encourage its teaching in European secondary schools, by development of an eLearning portal and virtual community, multimedia eLearning content, a content repository, and translation and dissemination in all 24 EU languages and 28 countries [21].

\section{RESULTS AND DISCUSSION}

\subsection{Agile stakeholder approach}

Stakeholder management must be particularly agile in today's complex organizational environments, characterized by multiple, ambiguous, uncertain and conflicting objectives, as well as methods to reach these objectives [22] [3] [23]. In modern organizations, stakeholders switch roles frequently between trainer and trainees. They contribute to the eLearning content as much as they benefit from it. Staff needs to learn and adapt fast. They cannot afford to take the long time-offs required for traditional training [10]; instead they need to find exactly the right piece of content needed on the spot. Using operations management terminology, this is Just-in-time Learning (JIT Learning) [24].

Traditionally, complex projects and programs are managed through systematic stakeholder management processes. At the same time, innovation is born out of loose, self-organized, complex teams, that exhibit chaos characteristics and experience emergence and black-swan phenomena [25] [26]. In fact, in order to be innovative, creative and changeable, a system must be taken away from equilibrium, and should make use of disorder, irregularity and difference for driving change [27].

Complex knowledge-building organizations work with organized centers of expertise, or communities of practice, which create and disseminate information and culture. Some of these groups are formal or semi-formal. They are emergent. They are often distributed and spread across different units and organizations.

The Circle of Knowledge concept represents formal or semi-formal communities of interest and expertise, with common interests, that exchange information and support building knowledge. They are moderated rather than managed; they function based on positive bottom-up incentives, rewardbased rather than task-based.

The members of these communities act both as trainers and trainees. The stakeholder relations in a Circle of Knowledge are varied and not necessarily strict. The main directions of influence between stakeholders are backwards and inwards (based on historical knowhow and constant feedback), as well as forwards (anticipating needs and trends) and outwards [28]. The Circles of Knowledge communities act thus as collaborative authoring teams of learning content.

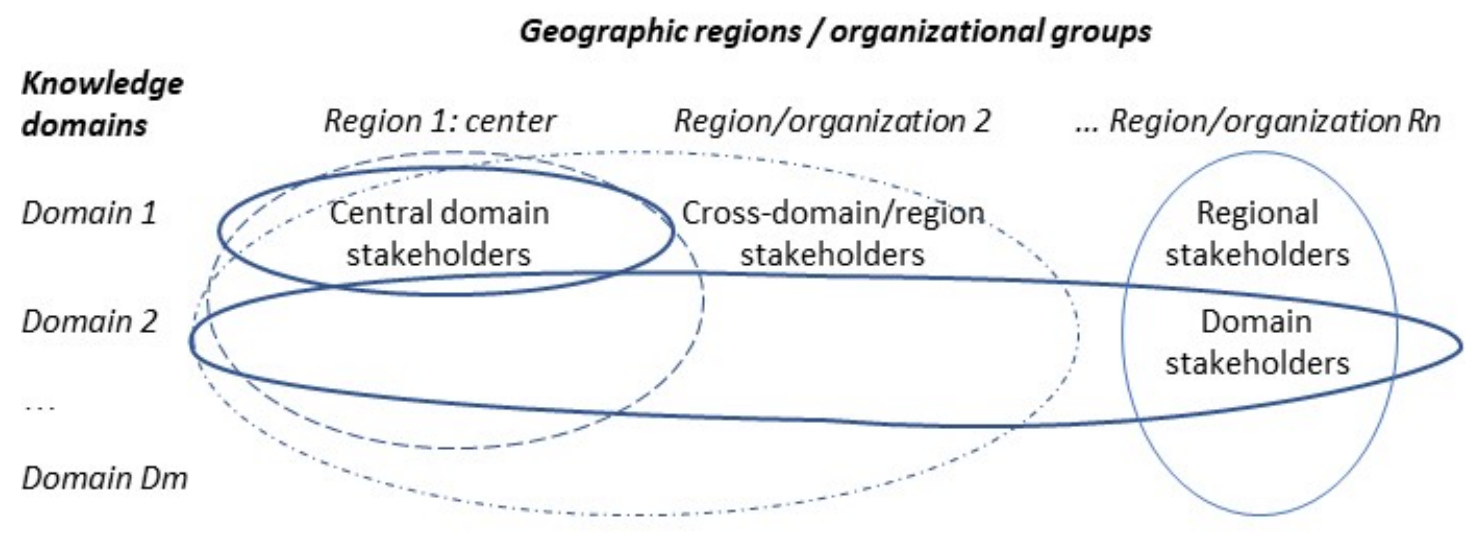

Figure 1. Circles of Knowledge concept 
The Circles of Knowledge concept is presented in the figure above, and is illustrated by several examples from the project cases below.

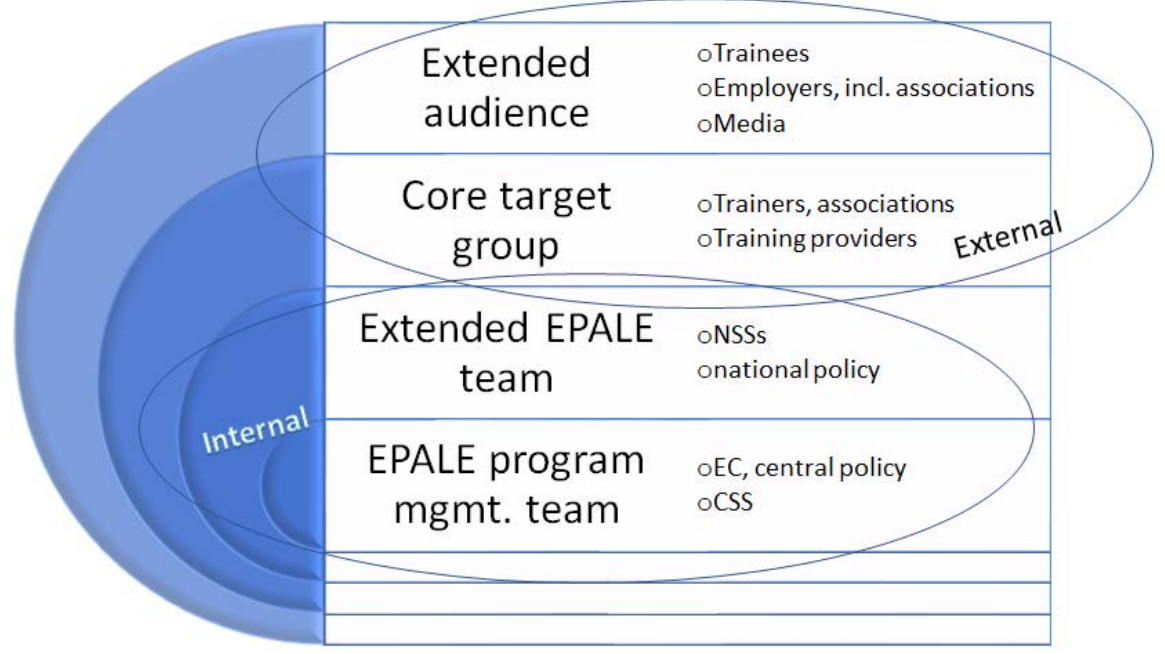

Figure 2. Circles of Knowledge: application to the project case EPALE

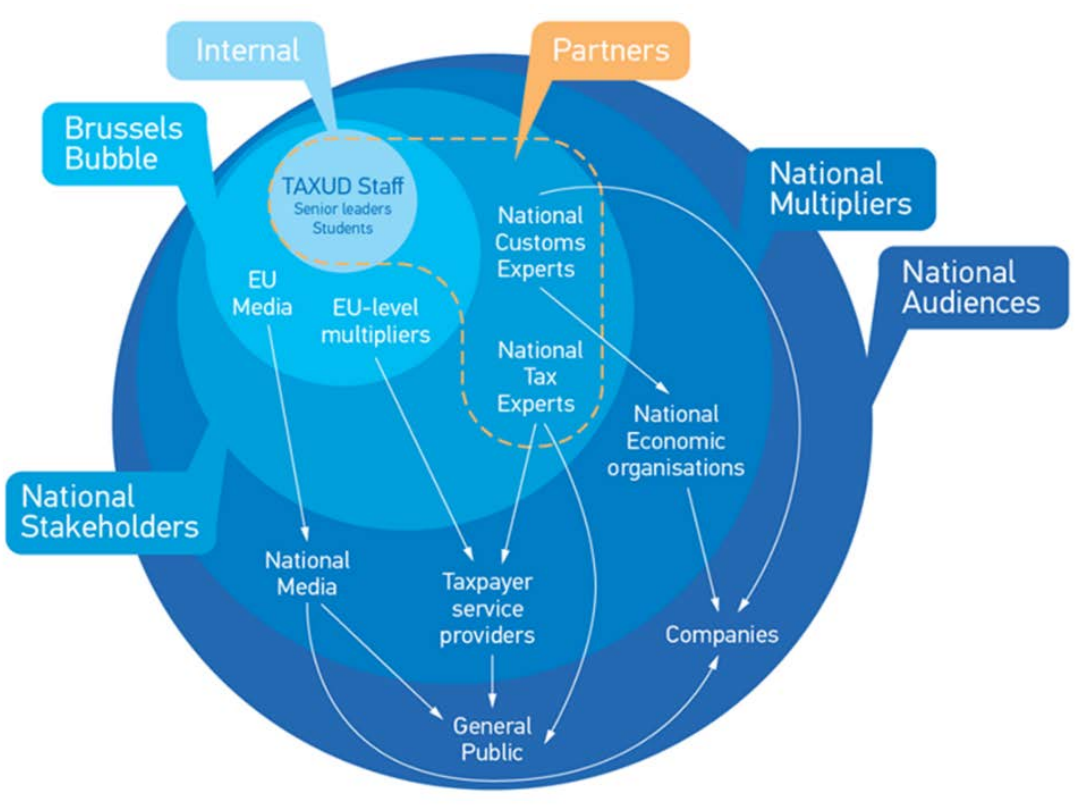

Figure 3. Circles of Knowledge: the Stakeholders Map of the B-Train project

\subsection{Agile content authoring and knowledge-building process}

Learning content has 2 main sources:

- Authoring specialized, professional eLearning courses;

- Building semi-structured knowledge bases.

Authoring specialized eLearning content is done using dedicated methodologies and tools. The Successive Approximation Model (SAM) Instructional Design Approach [29] [30] is more suitable to today's agile learning environments. SAM is more agile compared to the traditional ADDIE (Analysis Design Development Implementation Evaluation). Agile content authoring makes extensive use of fast prototyping, rapid delivery cycles and Design Thinking [31]. Modern collaborative authoring such as Articulate 360 or Adobe Captivate support both development of rich interactive courses as well as minimalistic courses, allow for interactive collaborative reviews and recording screencasts. 
Generic knowledge-bases support building indexed semi-structured or non-organized searchable databases, from many small heterogenous pieces of information, in any form or format, including basic text, graphic and video content - mostly small bits of information, also known as nano-learnings or micro-learnings. Ad-hoc pieces of information form dynamic emergent knowledge bases. These adapt and grow continuously. Content is thus created using wiki, blogs, incident databases, translation tools, shared glossaries to support common language and terminology.

The collaborative content authoring process and platform are built and deployed on agile principles, and use agile principles for all processes and products. Deployment of an agile learning environment requires agile project management and planning methodologies, agile release management tools such as Jira, Cl/CD platforms to support an overall agile development process to all content authoring subprocesses; including design, storyboarding, development of complex multimedia eLearning content, translation, localization, maintenance, continuous build, testing, integration and deployment. Collaboration, planning, supporting agile development, management of agile sprints and releases for authoring content collaboratively can be based on the Kanban board principle, with a multidimensional matrix of dependencies between deliverables and stakeholders involved in the process.

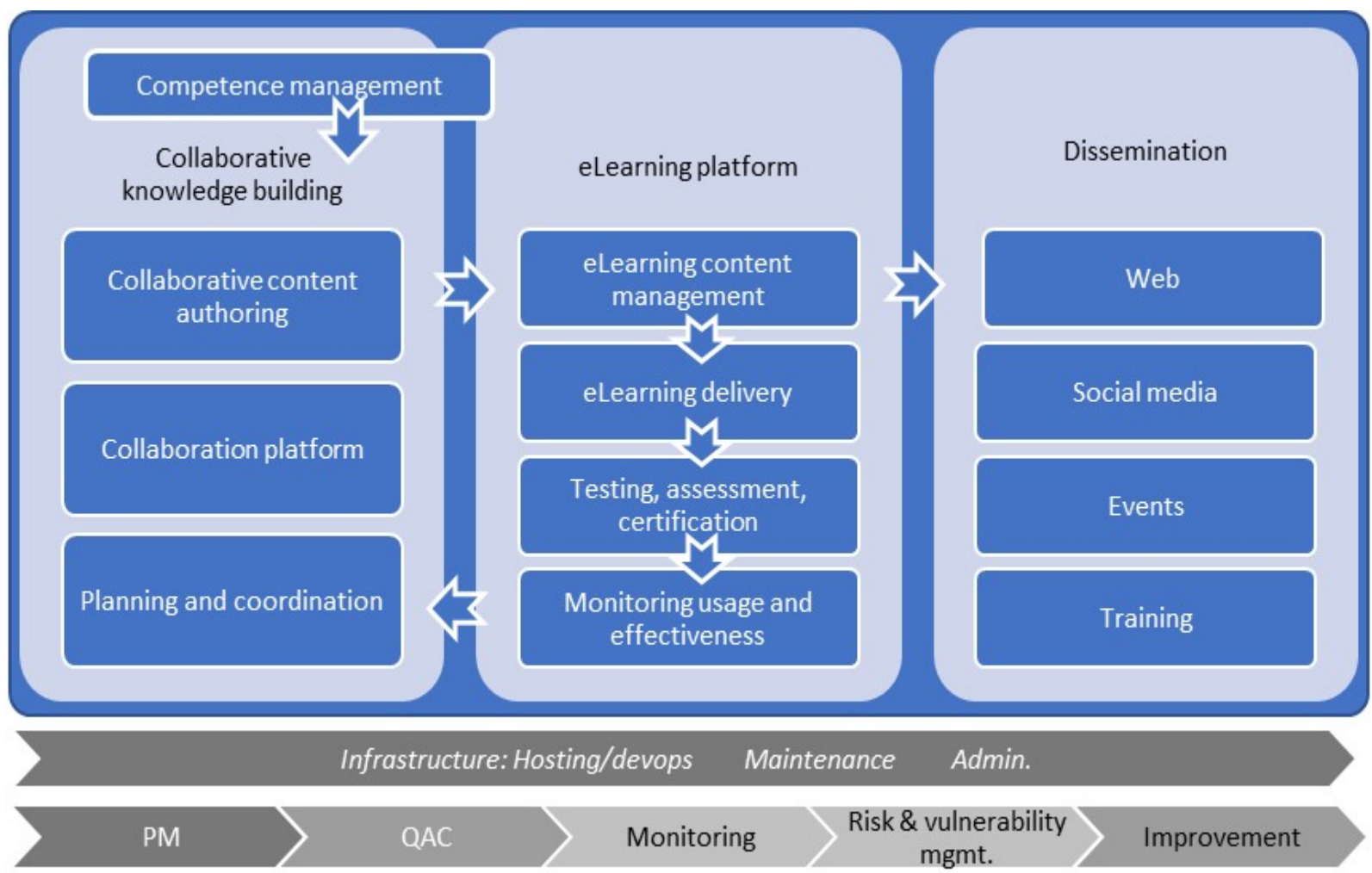

Figure 4. Agile Learning Environment concept

A conceptual architecture for the modern agile eLearning environment is presented in the figure above, and illustrated for several project cases below. 


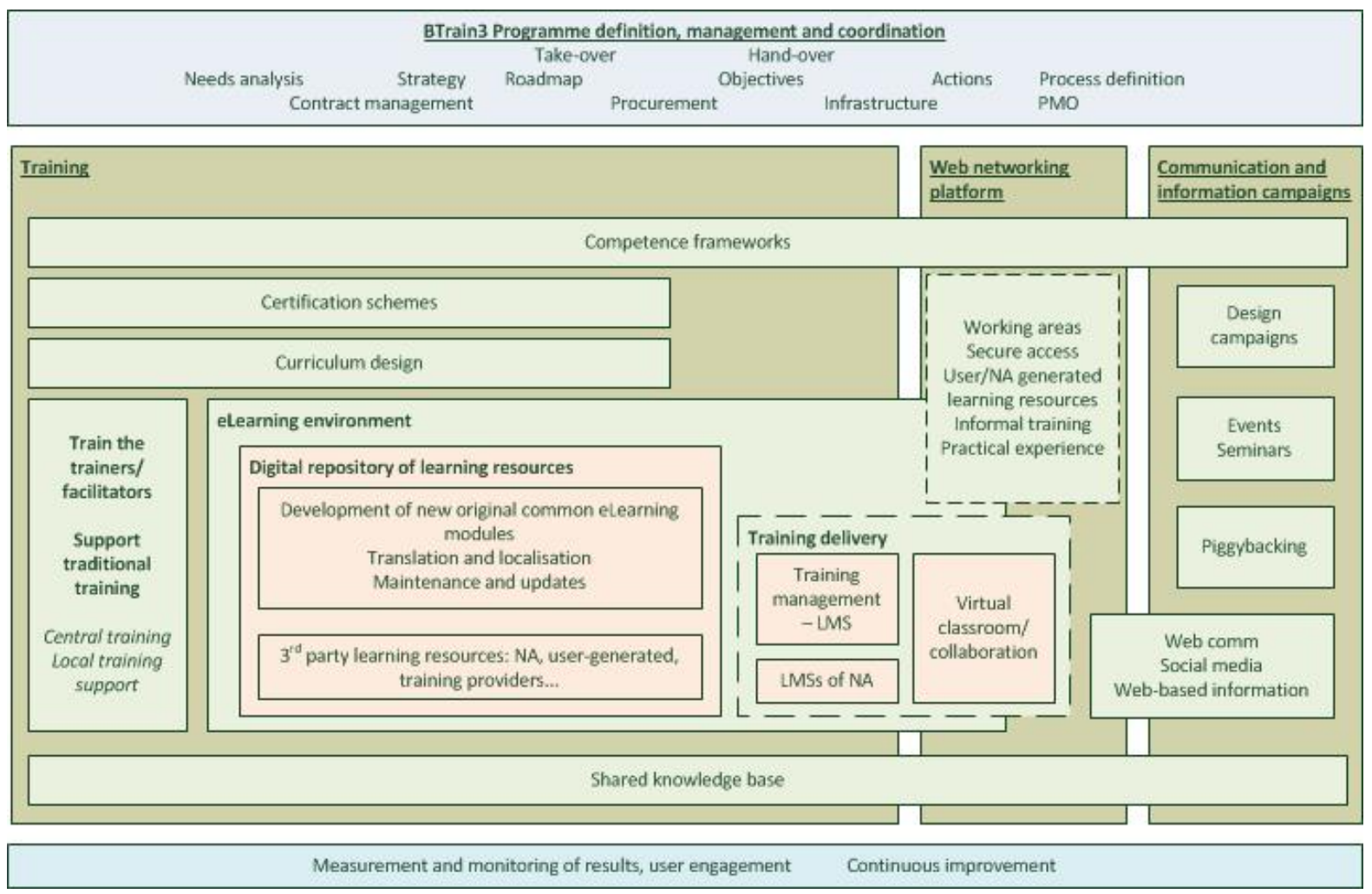

Figure 5. The vision for the European Learning Environment (ELE) architectural concept, of the EU customs and taxation - the B-Train programme [20]

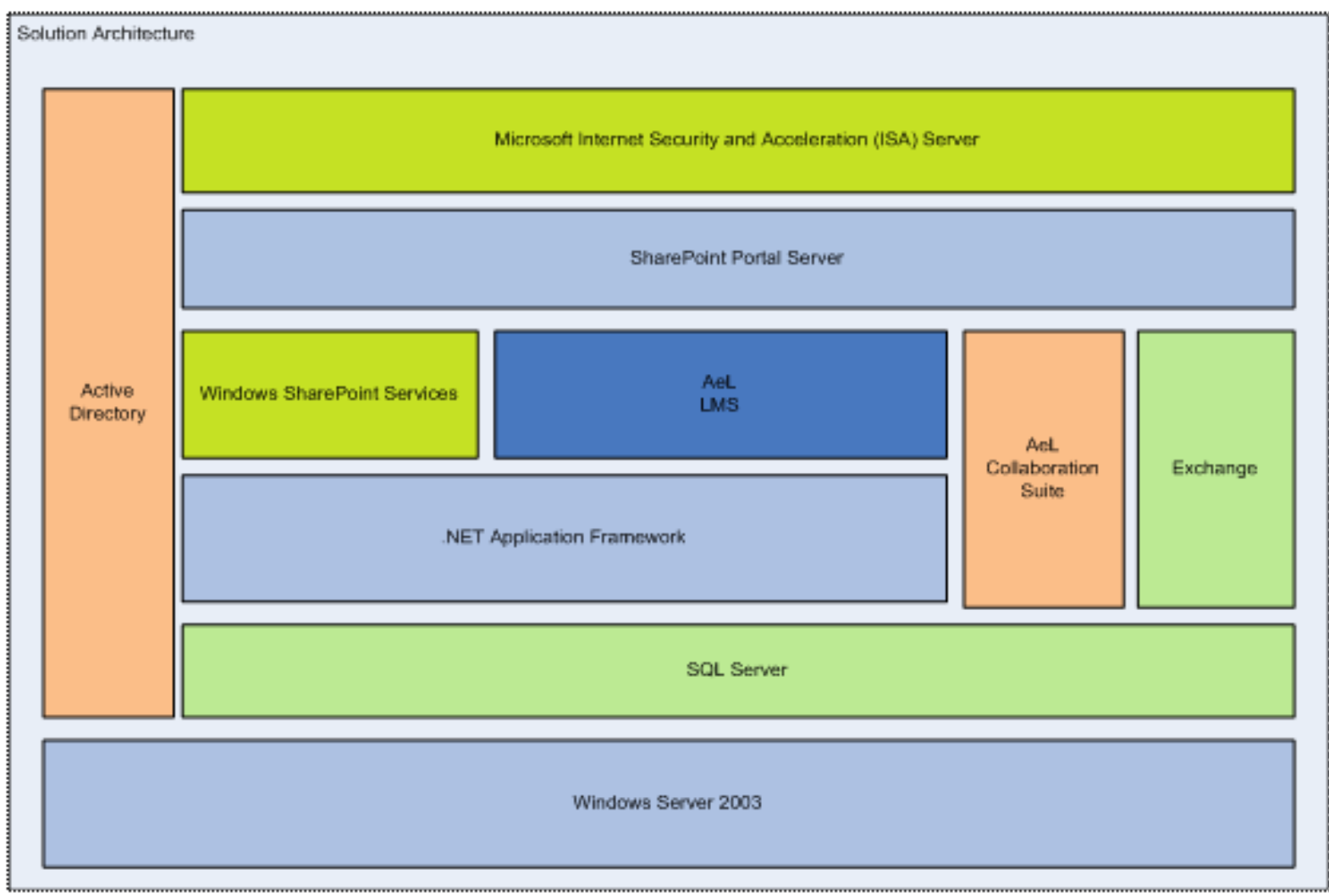

Figure 6. Cyprus DIAS project - conceptual architecture [32] 


\subsection{Agile eLearning and learning content}

Learning agility goes well beyond content authoring or platform deployment processes. Enddeliverables are formed of agile content and agile learning, supporting the delivery of granular pieces of information that are proven to be more easily digestible by today's users, thereby maximizing the effectiveness of the platform and learning process. Agile learning therefore requires moving from the traditional hours long courses, to small pieces of information, accessible when needed (JIT learning).

eLearning has long been dominated by the Reusable Learning Objects (RLO) philosophy to enhance agility [33]. SCORM [34] with its RLOs is exceptionally powerful and respected for its capacity for standardization and for its versatility. Standardization remains a requirement for content and platforms, including SCORM compliance, as well as other interoperability and packaging standards, such as IMS, x-api for LRS integration, ChemML, MathML etc. SCORM and similar standards delivered on their promise of interoperability, and partially delivered reusability. But the RLO paradigm has shown significant limitations and did not deliver on its promise of agility. The RLO is intrinsically simply not agile enough for today's learning needs, both in terms of content authoring as well as delivery. Adult learning requires micro- or nano-bits of information, which are created, delivered and digested on-thespot, Just-in-time.

Digital learning offers numerous possibilities as regards the form and delivery of content - especially in terms of multimedia and interactivity. eLearning has long been associated with highly interactive and rich-multimedia content. Still, the basic pedagogic principle should remain that content should not be only fashionable and appealing, but it needs to be mostly effective. It is time to revert back to basics: eLearning is learning [14]. Use of multimedia for the sake of multimedia is a waste of resources - the modern user experience is designed as fit-for-purpose.

eLearning thus reverts to basic principles: Covey's "begin with the end in mind" [35], as well as Occam's razor principle of simplicity, in order to design, develop and deploy whatever type of content that supports learning and knowledge building, in whatever form and format best suitable.

\subsection{Delivery: Agile Learning}

Learning delivery was traditionally a unidirectional process, from trainer to trainee, with feedback loops for monitoring, evaluation and improvement. In today's organizations, the barrier between trainer and trainee is not always clear. Agile stakeholder management means that trainers become trainees, and trainees become trainers, depending on the learning context, in an agile collaborative learning environment.

- The key stakeholders, i.e. the Who's, are thus agile.

- The delivery, i.e. the When, is agile: the platform allows for trainees to access content and ask for support whenever they need it.

- The location of delivery, i.e. the Where, is agile. Trainers and trainees access the content and platform from anywhere, with particular emphasis on mobile platforms. $75 \%$ of employees use mobile learning and $99 \%$ of mobile learners believe the mobile format enhances their learning [36] [37] [38].

Today's eLearning solutions such as Moodle are suitable to serve as agile learning delivery platforms. Modern eLearning platforms include video/audio conferencing, screen sharing, app sharing and whiteboarding, such as Slack, Skype and Google Hangouts, productivity tools such as Menti.com for quick, live surveys; Workflowy.com, Microsoft OneNote, Google Docs or Minutes.io for collaborative notes and minutes of meetings.

\subsection{Agile project implementation, management, support and improvement}

According to systems theory, complex products are implemented in complex organizations through complex projects and programs. Agile, incremental and iterative processes are valid solutions for managing project complexity. Agile implementation principles are supported by frameworks and tools such as Scrum, Kanban or Rational Unified Process (RUP).

Agile projects adapt and respond better to environmental changes, and are able to exploit opportunities associated with complexity, such as emergence, innovation and creativity. Examples of positive complexity effects are the appearance of ad-hoc learning groups by mixing team-members with different expertise (organizational complexity, process-related), solutions or ideas emerging from 
analyzing new perspectives in cross-disciplinary teams, products or content being used by users differently than intended (technological complexity, product-related), a product going viral unexpectedly (external environmental complexity, product-related) [39].

Implementing complex projects as programs has significant advantages: strategic importance and focus, access to power sponsors, agility [40] [41]. Individual projects part of larger programs are smaller and shorter, hence more agile, with clearer results, easier to measure, more transparent. In fact, all project cases analyzed during this research were implemented as programs, with multiple phases and iterations, with sequential or parallel project streams, following a common global strategy.

\section{CONCLUSIONS}

This paper presented a new holistic integrated approach to modern Agile Learning Environments and to stakeholder management in complex learning programs, projects and organizations. These support collaborative knowledge building in a world more and more dynamic and complex.

The modern eLearning environment is grounded on an overall agile paradigm. Agility is a powerful tool to tackle the increasing complexity that manifests in all aspects of society. A holistic approach is required, combining system thinking elements, such as the correlation between project complexity, product, process and organizational complexity.

Today's complex projects, programs and organizations are characterized by multiple, ambiguous, uncertain and conflicting objectives, as well as multiple methods to reach these objectives. While complexity poses significant challenges, complexity is often associated with innovation and emergence [25] [42]. The complexity of today's technological and learning environments creates opportunities that must be exploited.

\section{REFERENCES}

[1] D. Baccarini, "The concept of project complexity, a review," International Journal of Project Management, vol. 14, no. 4, pp. 201-204, 1996.

[2] J. D. McKeen, T. Guimaraes and J. C. Wetherbe, "The Relationship between User Participation and User Satisfaction: An Investigation of Four Contingency Factors," MIS Quarterly, vol. 18, no. 4, pp. 427-451, Dec 1994.

[3] T. M. Williams, "The need for new paradigms for complex projects," International Journal of Project Management, vol. 17, no. 5, pp. 269-273, 1999.

[4] W. Xia and G. Lee, "Complexity of Information Systems Development Projects: Conceptualization and Measurement Development," Journal of Management Information Systems, vol. 22, no. 1, pp. 45-83, 2005.

[5] S. J. Whitty and H. Maylor, "And then came Complex Project Management (revised)," International Journal of Project Management, no. 27, p. 304-310, 2009.

[6] J. Piaget, Psychology and Epistemology: Towards a Theory of Knowledge, New York: Grossman, 1971.

[7] M. D. Eddy, "Fallible or Inerrant? A Belated review of the "Constructivist Bible," British Journal for the History of Science, vol. 37, p. 93-8, 2004.

[8] M. Scardamalia and C. Bereiter, "Knowledge Building," in Encyclopedia of Education. 2nd edition, New York, Macmillan Reference, 2003.

[9] S. Morcov, "Collaborative knowledge building," 18 Oct 2019. [Online]. Available: https://blog.tremend.com/collaborative-knowledge-building/.

[10] B. Spar and R. Lefkowitz, "2018 Workplace Learning Report," Linkedln, 2018. [Online]. Available: https://learning.linkedin.com/resources/workplace-learning-report-2018. [Accessed 23 Dec 2019].

[11] S. Morcov, "Welcome to TALE: Tremend's Agile Learning Environment," 16 Oct 2019. [Online]. Available: https://blog.tremend.com/welcome-to-tale-tremends-agile-learning-environment/.

[12] S. Downes, "E-learning 2.0," ACM, Oct 2005. [Online]. Available: http://www.elearnmag.org/ subpage.cfm?section $=$ articles\&article $=29-1$. [Accessed 5 Jan 2020]. 
[13] T. Karrer, 10 Feb 2006. [Online]. Available: http://elearningtech.blogspot.com/2006/02/what-iselearning-20.html. [Accessed 05 Jan 2020].

[14] S. Morcov, "Complex IT Projects in Education: The Challenge," International Journal of Computer Science Research and Application, vol. 2, no. 1, pp. 115-125, 2012.

[15] J. Geraldi, H. Maylor and T. Williams, "Now, let's make it really complex (complicated): A systematic review of the complexities of projects," International Journal of Operations \& Production Management, vol. 31, no. 9, pp. 966-990, 2011.

[16] F. Marle and L.-A. Vidal, Managing complex, high risk projects - a guide to basic and advanced project management, London: Springer-Verlag, 2016.

[17] H. Levitt, M. M. Bamberg, J. W. Creswell, D. M. Frost, R. Josselson and C. Suárez-Orozco, "Journal Article Reporting Standards for Qualitative Primary, Qualitative Meta-Analytic, and Mixed Methods Research in Psychology: The APA Publications and Communications Board Task Force Report," American Psychologist, vol. 73, no. 1, pp. 26-46, 2018.

[18] M. Gibbert and W. Ruigrok, "The "What" and "How" of Case Study Rigor Three Strategies Based on Published Work," Organizational Research Methods, 2010.

[19] European Commission - EACEA, "Procurement documents - EACEA/2019/01 - EPALE (Electronic Platform for Adult Learning in Europe): Central Support Service," 3 May 2019. [Online]. Available: https://etendering.ted.europa.eu/cft/cft-display.html?cftld=4700.

[20] European Commission - DG Taxud, "Procurement documents - TAXUD/2019/OP/0002 Framework Contract for the Provision of Expert Services Supporting Multifaceted EU Training and Staff Development in Customs and Taxation (B-TRAIN4)," 3 Jun 2019. [Online]. Available: https://etendering.ted.europa.eu/cft/cft-display.html?cftld=4752\&locale=en.

[21] SIVECO Romania, "How to be a well-informed consumer," 18 Dec 2014. [Online]. Available: http://www.siveco.ro/en/about-siveco-romania/press/press-releases/how-to-be-a-well-informedconsumer.

[22] J. Turner and R. Cochrane, "Goals-and-methods matrix: coping with projects with ill defined goals and/or methods of achieving them," International Journal of Project Management, no. 11, pp. 93102, 1993.

[23] College of Complex Project Managers And Defence Materiel Organisation, Competency Standard for Complex Project Managers, Version 2.0 ed., 2006.

[24] M. Riel, "Education in the 21st Century: Just-in-Time Learning or Learning Communities," in Challenges of the Next Millennium: Education \& Development of Human Resources. The Fourth Annual Conference of the Emirates Center for Strategic Studies and Research, May 24-26, 1998.

[25] S. Floricel, J. L. Michel and S. Piperca, "Complexity, uncertainty-reduction strategies, and project performance," International Journal of Project Management, vol. 34, no. 7, pp. 1360-1383, Oct 2016.

[26] N. N. Taleb, The Black Swan: The Impact of the Highly Improbable, Random House, 2007.

[27] R. D. Stacey, "The Science of Complexity: An Alternative Perspective for Strategic," Strategic Management Journal, vol. 16, no. 6, p. 477-495, 1995.

[28] L. Bourne, "Project relationships and the Stakeholder Circle," Montréal, Québec, Canada, 2006.

[29] M. Allen and R. Sites, Leaving ADDIE for SAM: An Agile Model for Developing the Best Learning Experiences, American Society for Training and Development, 2012.

[30] W. Sirui, "The Instructional Design Model That Best Fits - SAM Model," 18 Aug 2018. [Online]. Available: https://learningbyclick.wordpress.com/2018/08/18/the-instructional-design-model-thatbest-fits-sam-model/. [Accessed 23 Dec 2019].

[31] J. E. Arnold, Creative Engineering: Promoting Innovation by Thinking Differently, 1959.

[32] S. Morcov, L. Pintelon and R. J. Kusters, "Challenges of implementing a large-scale eLearning and collaboration platform - the DIAS project, Cyprus," in Conference proceedings of "eLearning and Software for Education" ELSE, 2012. 
[33] Cisco Systems, "Reusable information object strategy," 30 May 2013. [Online]. Available: https://web.archive.org/web/20130530223125/http://www.cisco.com/warp/public/779/ibs/solutions/ learning/whitepapers/el_cisco_rio.pdf .

[34] ADLnet, "Advanced Distributed Learning Initiative," 03 Jan 2020. [Online]. Available: https://adlnet.gov/.

[35] S. R. Covey, The Seven Habits of Highly Effective People: Restoring the Character Ethic, New York: Simon and Schuster, 1989.

[36] R. Skilbeck, "Top 11 learning trends for 2019," 01 Feb 2019. [Online]. Available: https://www.pageuppeople.com/resource/top-11-learning-trends-for-2019/.

[37] T. Tauber, T. Smolen, C. Probst and M. Huang, "How the workforce learns in 2016," 2016. [Online].

Available: https://get.degreed.com/hubfs/Degreed_How_the_Workforce_Learns_in_2016.pdf.

[38] S. Johnson, "Top 5 Corporate Learning Trends for 2016 (Infographic)," 24 Feb 2016. [Online]. Available: https://elearninginfographics.com/top-5-corporate-learning-trends-2016-infographic/13/.

[39] S. Giles, The New Science of Radical Innovation: The Six Competencies Leaders Need to Win in a Complex World, Dallas, TX: BenBella Books, 2018.

[40] P. Ribbers and K. Schoo, "Program Management and Complexity of ERP Implementations," Engineering Management Journal, vol. 14, no. 2, pp. 45-52, 2002.

[41] K. Remington and J. Pollack, Tools for complex projects, London: Gower Publishing Ltd, 2007.

[42] M. Eriksson, J. Lillieskoeld, N. Jonsson and D. Novosel, "How to manage complex, multinational R\&D projects successfully," Engineering Management Journal, vol. 14, no. 2, pp. 53-60, 2002.

[43] T. Williams, "The Nature of Risk in Complex Projects," Project Management Journal, vol. 48, no. 4, p. 55-66, 2017.

[44] N. N. Taleb, D. G. Goldstein and M. W. Spitznagel, "The Six Mistakes Executives Make in Risk Management," Harvard Business Review, 2009. 